PALAVRAS. Revista de Epistemología, Metodología y Ética del Psicoanálisis

ISSN: $2468-9831$

www.revistas.unlp.edu.ar/palavras

palavras@outlook.com.ar

Argentina

\title{
IDENTIDADE, SIGNIFICAÇÃO E INTERCORPOREIDADE NA OBRA INICIAL DE FREUD
}

DOI $10.24215 / 24689831 \mathrm{e} 010$

Richard Theisen Simanke

\begin{abstract}
The introduction of the concept of intersubjectivity in psychoanalysis - such as it paradigmatically took place in Lacanian psychoanalysis - aimed at providing a counterpoint to the objectivism supposedly present in Freud's work, mainly because of its epistemological roots in nineteenth-century medicine and natural sciences. From this perspective, this objectivism should be more intense in Freud's early work, for example, in the moment of transition of his neurological work to psychoanalysis. On the other hand, when Merleau-Ponty introduces de concept of intercorporeality, he sought to avoid the excessively idealistic aspects of the theories of intersubjectivity then prevailing in the French context (neo-Hegelian and Husserlian) and replace them by a more embodied version of the constitutive relationship between subjects. The objective here is to show that something very close to Merleau-Ponty's concept of intercorporeality can be found in Freud's early work - that is, in the moment when he is supposedly more committed to a scientist objectivism. Two issues are discussed in this context - the early constitution of identity (the sense of the self) and the origins of meaning - to show how Freud conceives of them as resulting from shared bodily experiences. In conclusion, it is argued that Freud's open epistemological naturalism does not necessarily commit him either to a naïve view of intersubjective and subject-object relationships, or to other conceptual mistakes ordinarily associated to this stance.
\end{abstract}

Key-words: Freud - intercorporeality - identity meaning - Project for a scientific psychology.
La introducción de la noción de intersubjetividad en el psicoanálisis -como sucedió paradigmáticamente, en el psicoanálisis lacaniano- estaba destinada a contrarrestar el objetivismo supuestamente presente en la obra de Freud, sobre todo debido a sus raíces epistemológicas en las ciencias naturales y la medicina del siglo XIX. Desde esta perspectiva, este objetivismo debería estar más presente en los primeros trabajos de Freud, por ejemplo, en el período de transición de su obra neurológica para el psicoanálisis. Por otro lado, cuando Merleau-Ponty introduce la noción de intercorporeidad, él pretende eludir los aspectos excesivamente idealistas de las teorias de la intersubjetividad entonces predominantes en la escena francesa (neohegeliana y husserliana, por ejemplo) y reemplazarlas con una versión más encarnada de la relación constitutiva entre los sujetos. El objetivo aquí es mostrar que algo muy cercano a la noción de intercorporeidad de Merleau-Ponty se encuentra presente desde el inicio de la obra de Freud, cuando supuestamente está más comprometida con un objetivismo cientificista. Dos problemas se discuten en este contexto - la formación inicial de la identidad (o del sentido de sí mismo) y los orígenes de la significación - para mostrar cómo Freud las concibe como derivadas de experiencias corporales compartidas. En conclusión, se argumenta que el naturalismo epistemológico declarado de Freud no necesariamente lo compromete con una visión ingenua de la relación intersubjetiva y de la relación sujeto-objeto, ni tampoco con otros errores conceptuales que normalmente se asocian con esta posición.

Palabras clave: Freud - intercorporeidad - identidad - significación - Proyecto de una psicología.

\section{Cómo citar este artículo:}

Simanke, R. T. (2016). Identidade, significação e intercorporeidade na obra inicial de Freud. Palavras. Revista de Epistemología, Metodología y Ética del Psicoanálisis, 2, 87-119. Recuperado de www.revistas.unlp.edu.ar/palavras 


\title{
IDENTIDADE, SIGNIFICAÇÃO E INTERCORPOREIDADE NA OBRA INICIAL DE FREUD ${ }^{1}$
}

\section{Richard Theisen Simanke*}

\begin{abstract}
Se queres sentir a felicidade de amar, esquece a tua alma. / A alma é que estraga o amor. / Só em Deus ela pode encontrar satisfação. / Não noutra alma. / Só em Deus - ou fora do mundo. / As almas são incomunicáveis. / Deixa o teu corpo entender-se com outro corpo. / Porque os corpos se entendem, mas as almas não. (Manuel Bandeira, A Arte de Amar).
\end{abstract}

\section{Objetivismo vs. intersubjetividade}

Este trabalho faz parte de um projeto mais geral, sobre o percurso do tratamento da questão da corporeidade na história da psicanálise, começando com as origens freudianas e seus desdobramentos posteriores $^{2}$. Ele dá continuidade e é complementar a outro trabalho ainda inédito - também relacionado a esse projeto, que consiste basicamente numa leitura crítica da visão lacaniana da corporeidade (Simanke, 2016). Não se trata de retomar esse trabalho aqui, mas apenas mencioná-lo como o ponto de partida de um dos aspectos do problema em foco, como se verá abaixo.

Trata-se, em primeiro lugar, de distanciar-se de certas leituras da psicanálise freudiana que se caracterizam por um olhar seletivo que procura distinguir entre um Freud contemporâneo e teoricamente

${ }^{1}$ Conferência proferida no IX Simpósio Internacional de Filosofia e Psicanálise (Vitória, 2014). Gostaria de agradecer o convite da Prof. Dra. Cláudia Murta para falar nessa ocasião, assim como a todos os presentes que participaram do debate pela sua contribuição ao desenvolvimento das ideias inicialmente formuladas - contribuição tanto mais valiosa por se tratar de um trabalho ainda em andamento e cuja formulação aqui apresentada é ainda provisória.

* Universidade Federal de Juiz de Fora (UFJF), Brasil. Mail: richardsimanke@uol.com.br. O autor agradece ao CNPq o apoio a esse trabalho sob a forma de Bolsa de Produtividade em Pesquisa concedida ao projeto Corpo, ciência e natureza na história da psicanálise, do qual se apresenta aqui uma parte dos resultados.

2 Uma exposição dos eixos principais desse projeto pode ser encontrada em Simanke (2015). 
interessante e outro nem tanto. A leitura lacaniana é bastante emblemática desse tipo de atitude e de estratégia de leitura que parte do princípio de que há coisas boas e valiosas em Freud, que precisam ser preservadas (e, até mesmo, defendidas contra outras interpretações), mas há também certos erros de percurso que teriam que ser corrigidos, até para que essas virtudes possam ser adequadamente apreciadas. Do ponto de vista retórico, no entanto, essa atitude seletiva é frequentemente disfarçada por um discurso pseudoortodoxo que enaltece a totalidade do pensamento de Freud, ao mesmo tempo em que projeta sobre o mesmo outros dispositivos teóricos que substituem ou traduzem os aspectos indesejados, tal como se manifesta exemplarmente no famoso "retorno a Freud" de Lacan (Simanke, 2002; 2003).

Desde essa perspectiva, um dos principais equívocos dos quais seria preciso depurar a psicanálise freudiana seria o seu objetivismo. Freud correria o risco de pôr perder suas virtudes conceituais, sejam quais forem aquelas que the sejam atribuídas, por causa da orientação objetivista da sua psicanálise. "Objetivismo", tomado no seu sentido mais geral, é um termo que designa certo tipo de atitude epistemológica (isto é, relativa ao problema do conhecimento). Segundo essa concepção, os objetos são como são; eles s situam no mundo externo, e as coisas acontecem na mente (ou na "subjetividade") dos observadores dependendo do tipo de relação que estes entretenham com esses objetos, que são supostos como existindo independentemente e com os quais, de alguma maneira, é preciso entrar em relação, seja como objetos de conhecimento, seja como objetos de desejo, ou qualquer outro tipo de atitude ou função intencional que o sujeito protagonize. $\mathrm{O}$ suposto objetivismo freudiano seria, então, uma concepção ingênua sobre a natureza do objeto psíquico e sobre a natureza da relação sujeito-objeto; em outras palavras, tratar-se-ia, basicamente, de um realismo ingênuo do objeto.

Se o que se pretende é resgatar Freud desse seu suposto objetivismo, é necessário um antídoto conceitual para o mesmo. Um dos principais 
antídotos que encontramos reivindicado por certas tradições psicanalíticas pós-freudianas, assim como por certas correntes intelectuais nas quais alguma espécie de recepção da psicanálise teve lugar, recorre à ideia de intersubjetividade. Tudo se passa como se, para salvar Freud de si mesmo, essas correntes e tendências sentissem a necessidade de introduzir uma ideia nova, que não se encontrasse como tal em Freud, mas que teria o miraculoso efeito de simultaneamente corrigir seus defeitos e fazer ressaltar suas virtudes e sua originalidade. Outra possibilidade é recusar o reconhecimento desses supostos defeitos e atribuir retrospectivamente a Freud o manejo dessa ideia redentora, ainda que de forma velada, criptica, vazando-a num vocabulário inadequado ou deliberadamente desencaminhador, de modo que apenas os mais sagazes intérpretes seriam capazes de reconhecê-la.

Mas o que, exatamente, se entende por intersubjetividade? Essa noção significa, basicamente, que o sujeito não se determina nem se constitui originariamente numa relação com seus objetos, mas sim numa relação com outros sujeitos, ou seja, que os sujeitos humanos constituemse mutuamente, numa rede ou sistema de interações recíprocas. Em outras palavras, a ideia de intersubjetividade coloca em segundo plano a relação entre sujeito e objeto e traz para o primeiro plano a relação sujeito-sujeito. A partir daí, há um pequeno passo a mais a ser dado para considerar a relação entre sujeitos - a relação "intersubjetiva" como constitutiva da própria subjetividade. Dito de outra maneira, não é tanto o caso de que os sujeitos existam por si sós, independentemente uns dos outros; nenhum sujeito, por assim dizer, nasce sozinho, isolado, fechado sobre si mesmo, mas, ao contrário, os indivíduos só se tornam sujeitos, só advêm como sujeitos - sujeitos psíquicos, sujeitos do imaginário, sujeitos do simbólico, do significante ou do que seja lá o que for que se suponha que eles sejam sujeitos - nas suas relações uns com os outros.

Tomando-se, então, mais uma vez, a orientação lacaniana como exemplar desse tipo de atitude, tratava-se, então, em todo um primeiro 
período da reflexão de Lacan sobre Freud, de inserir ou acrescentar essa ideia de intersubjetividade ao corpo de conceitos freudianos. (Mais tarde, Lacan desistiu dessa ideia, sobretudo no que diz respeito à fundamentação da clínica psicanalítica, e aí é preciso que nos perguntemos por que ele a abandonou e o que fez a partir de então, quais outras noções vieram ocupar o seu lugar, mas isso é assunto para outra ocasião $\left.{ }^{3}\right)$. Em todo caso, essa atitude fez escola e é ainda um discurso recorrente - até mesmo insistente - em muitas tradições psicanalíticas, em que falar de "relação de objeto" é praticamente uma heresia.

Qual é o problema de se fazer isso? $O$ ponto principal reside na concepção específica de intersubjetividade que foi assim introduzida na psicanálise freudiana. É claro que, para além da sua definição geral exposta acima - uma relação constitutiva entre sujeitos -, é possível distinguir diversas concepções de intersubjetividade, correlativas, inclusive, a diferentes concepções sobre o que se considera um sujeito. Para ficarmos com a visão lacaniana, que estamos tomando como emblemática desse tipo de reinterpretação de Freud, ela, como toda opção teórica, tem certas consequências. Essas opções têm certo custo; há um preço a pagar, por assim dizer, em termos de consequências às quais a teoria, de alguma maneira, precisa fazer frente.

Uma das consequências para a qual se pode chamar atenção é aquilo que, no trabalho sobre Lacan mencionado anteriormente, eu chamei de neutralização do corpo na psicanálise lacaniana, isto é, a supressão de uma referência mais efetiva à corporeidade no âmbito da teoria e na maneira como esta aborda os fenômenos da subjetividade. Qual a razão pela qual isso ocorre? Para responder essa pergunta, mesmo que brevemente, é preciso levar em consideração o contexto histórico e intelectual em que essa concepção de intersubjetividade toma forma e no qual se dá a recepção dessa noção por parte da psicanálise. Nesse

\footnotetext{
${ }^{3}$ Ver Safatle (2005) para uma análise detalhada desse redirecionamento crucial no percurso teórico de Lacan.
} 
caso, essa ideia de intersubjetividade tem uma origem bastante precisa: ela surge no contexto do neo-hegelianismo francês, isto é, no contexto de certa interpretação do pensamento hegeliano em sua recepção francesa nas primeiras décadas do século 20 - no final dos anos 1920 e ao longo dos anos 1930, mais precisamente. Essa recepção teve certas características bem peculiares, e uma delas foi fazer do pensamento hegeliano - ou, pelo menos, daqueles aspectos da filosofia de Hegel que foram mais enfatizados e valorizados - uma espécie de antropologia filosófica. Mais precisamente, essa maneira de interpretar uma parte da obra hegeliana - basicamente, a Fenomenologia do espirito (Hegel, 1807 / 1941), além de outras obras em que a temática apresentada ali é desenvolvida - tendia a compreender o que se formula ali como uma teoria da antropogênese, isto é, como uma teoria sobre como sujeitos humanos aparecem no mundo, como eles surgem num mundo que inicialmente não os contém.

Esse tipo de problema conduz mais ou menos espontaneamente à tese de que o aparecimento de um sujeito especificamente humano no mundo se dá por um processo de ruptura com relação a esse mundo não humano que se supõe existindo antes de sua entrada em cena. Um mundo que não contenha a humanidade é, por definição, um mundo não humano, de tal maneira que surgimento desse elemento humano pressupõe a transformação de algo nesse mundo numa coisa diferente ontologicamente diferente, para ser mais preciso - do que era até então.

Que tipo de problema isso cria com relação à questão da corporeidade? Classicamente, essas entidades de cujo encontro nasce o que reconhecemos como a humanidade (o conjunto de propriedades que torna humanos os seres humanos, na sua diferença essencial com as outras entidades não humanas que habitam o mundo) - esses seres, enfim, em via de se tornarem sujeitos são pensados, naquilo que interessa ao processo de humanização, como puras consciências. Nesse tipo de reinterpretação da dialética hegeliana, a concepção desses sujeitos de cujo embate nasce o mundo propriamente humano é despojada de toda e qualquer materialidade, tanto com relação aos 
elementos do mundo que motivam a sua ação (como se verá a seguir), quanto com relação à sua própria existência enquanto seres materiais ou corpóreos (não que se desconheça que os individuos tenham corpos, é claro, mas esses corpos não desempenham nenhum papel significativo no processo ${ }^{4}$ ).

Pensemos, por exemplo, na interpretação kojèviana da Fenomenologia do espírito, a leitura feita no seminário de Alexander Kojève, que foi, pode-se dizer, o principal mentor intelectual de Lacan quanto a essas questões. Na interpretação de Kojève (1947/2002), esses protagonistas são sempre pensados como consciências puras: eles comparecem nesse encontro como consciências que se confrontam, mas nunca como corpos. Não são corpos que se defrontam, mas sim consciências em formação. Isso se torna mais peculiar quando se leva em conta que, na perspectiva kojèviana, esse encontro não é pensado como algo amigável ou como um encontro feliz. Ao contrário, esse encontro é pensado como uma luta e, mais do que isso, como uma luta até a morte. Deixando de lado por ora a razão pela qual as coisas têm que ser pensadas dessa maneira, cabe observar apenas que, se esse encontro do qual deve nascer o mundo humano - esse encontro entre sujeitos que, na verdade, se constituem por esse encontro - tem que ser uma luta, não se trata da luta por alguma coisa pré-existente no mundo; em outras palavras, não se trata de uma luta por um objeto. Os sujeitos kojèvianos - e os sujeitos lacanianos, por extensão - nunca lutam por alimento, ou por território, ou por um parceiro sexual. Eles lutam por outra coisa que não é um objeto, mas um valor exclusivamente imaginário, que Kojève denominou puro prestigio. Essa luta humanizante entre duas consciências que se confrontam é, portanto, definida como uma luta de

\footnotetext{
4 Tipicamente, a corporeidade é pensada como desempenhando um papel exclusivamente negativo no processo de humanização, como algo que precisa ser superado, negado e ultrapassado. Daí que, por exemplo, na leitura kojèviana que se comenta na sequência, a ênfase seja colocada na negação da vida animal como valor, na superação do medo da morte (perda da vida animal) na luta pelo reconhecimento, e assim por diante.
} 
puro prestigio (sendo esse um mote kojèviano que Lacan, aliás, repete à exaustão).

A razão pela qual eles não podem lutar por uma coisa, por um objeto do mundo, é que o vencedor deve, em princípio, se apropriar do prêmio por sua vitória e consumi-lo. Ao consumi-lo, sua natureza se transforma em função da natureza daquilo que ele consome. Se ele, portanto, consumir um objeto do mundo natural, não estará progredindo em direção a uma condição propriamente humana, mas retornando ou permanecendo num estado de natureza. É por isso que, para ser, para se tornar e permanecer humano, o indivíduo não pode consumir e desejar uma coisa. Mas, até agora, só existem coisas no mundo; até os seres proto-humanos que se confrontam não são ainda ontologicamente distintos das coisas (já que ainda não são humanos). Sua individualidade é, como diz Kojève, a de um "eu coisista". A única alternativa é que esse ser em vias de humanização só pode desejar, em última instância, nada. Mais precisamente, ele só pode desejar o próprio desejo, mas o desejo em si mesmo não é nada, é apenas um movimento, um voltar-se para algo visado como objeto, um vazio ou uma carência que aspira por ser preenchida. O próprio desejo, no entanto, não é coisa alguma, no sentido positivo do termo, mas sim, como numa das frases que Kojève usa para caracterizá-lo em seus cursos de reinterpretação da fenomenologia hegeliana, trata-se de "um nada revelado" 5 .

Pode-se dizer, então, desses sujeitos que se constituem dessa maneira, que eles não tenham corpos; melhor dizendo, tudo se passa como se eles não tivessem corpos, seus corpos não contam para nada no processo. Pelo contrário, é necessário que a vida animal desse ser proto-humano seja ativamente negada, seja recusada como um valor,

5 "Porque o desejo considerado como desejo, isto é, antes de sua satisfação, é apenas um nada revelado, um vazio irreal" (Kojève, 1947/2002, p. 12). Uma excelente abordagem da leitura kojèviana de Hegel centrada nessa concepção do desejo como negatividade e sua função humanizante pode ser encontrada em Descombes (1979/1998), em seu primeiro capítulo, intitulado, justamente, "A humanização do nada". 
para que o processo possa avançar. É por isso que, na visão kojèviana, essa luta tenha que ser uma luta até a morte: o sujeito tem que estar disposto a sacrificar sua vida animal no esforço de fazer o outro reconhecê-lo como humano. Se ele não fizer isso, se ele parar no meio do caminho, se o medo da morte fizer com que ele hesite ou retroceda, ele não se tornará um ser totalmente humano, mas permanecerá como que num estágio intermediário entre o homem e o animal, submisso ao desejo de outro, nessa condição que Hegel identificou como 'a posição do Escravo', em contraste com a posição do Mestre ou Senhor. Lacan vai, caracteristicamente, recorrer a essa condição como metáfora para representar a situação existencial do neurótico. Para ele, o neurótico - o obsessivo, sobretudo - está na mesma posição que o Escravo hegeliano. Ele se encontra numa espécie de impasse existencial, tendo avançado até certo ponto no processo de constituição enquanto sujeito, mas se detido em algum lugar no meio do caminho, por não ter sido capaz de assumir plenamente o seu ser-para-a-morte, no sentido heideggeriano ${ }^{6}$. É nesse sentido que Lacan interpreta a procrastinação típica do obsessivo, os sucessivos adiamentos daquilo que este se propõe ou julga que deve fazer, que se traduzem nas idas e vindas de sua conduta e na ritualização sistemática da vida (há sempre um ritual a ser executado antes que uma decisão possa ser tomada ou uma ação empreendida). Sua vida se torna uma espera, como diz Lacan (1975), porque ele não consegue se decidir a pagar o preço pela plena assunção de seu desejo, que é reconhecer plenamente a própria mortalidade, renunciar à sua vida animal - à vida de seu corpo animal - como um valor.

Torna-se bastante claro, então que essa recusa de um suposto objetivismo presente na versão original da psicanálise tal como formulada por Freud - uma recusa que lança mão da ideia de intersubjetividade como ferramenta teórica -, tem, como consequência, essa neutralização de uma referência efetiva à corporeidade na

\footnotetext{
${ }^{6}$ Não é Lacan que introduz Heidegger por conta própria aqui: a leitura que Kojève faz da Fenomenologia do espírito já é marcada por um sensível viés heideggeriano (Macherey, 1991; Simanke, 2005).
} 
construção da teoria. Isso é bastante visivel no percurso de Lacan, em que o corpo aparece sempre como um elemento incômodo, como a peça que sobra e não se encaixa na montagem de sua teoria do sujeito. Assim como para Descartes, o corpo, para ele, não age, não atua por si mesmo. No limite, o corpo não tem vida própria: o corpo, sem alma, é como um cadáver, diz Descartes, e Lacan, significativamente, usa mais de uma vez a referência ao cadáver como metáfora para falar da corporeidade ${ }^{7}$. Em suma, para ambos, o corpo tem que ser animado de fora: não há uma potência do corpo para Lacan, toda a sua força ou capacidade de agir e produzir efeitos no mundo tem que vir de outro lugar. O corpo tem que ser animado por algo que não seja corpóreo. Em Descartes, essa função, é claro, é desempenhada pela alma; o corpo lacaniano, por sua vez, tem que ser animado ora pela imagem, ora pela letra (o "significante" lacaniano), mas sempre por algo que pertença a outra ordem de determinação, caso contrário jamais um sujeito advém nesse corpo que, por si só, é impotente para lhe dar origem.

No esquema kojèviano, assimilado e adaptado por Lacan, existe evidentemente uma animalidade, mas essa animalidade é parte do mundo dado, do mundo não histórico, do mundo natural - e não do mundo humano. Essa animalidade tem que ser negada, tem que ser de certa maneira consumida na realização do mundo humano. O famoso aforismo hegeliano, formulado nas suas conferências de Jena sobre a "Realphilosophie", que afirma que "a doença do animal é o vir-a-ser do

\footnotetext{
${ }^{7}$ A identificação entre o corpo, quando considerado fora de sua relação com a alma, e o cadáver - e, portanto, a negação de uma autonomia da vida - é explícita em Descartes. Por exemplo, diz ele, na Segunda Meditação: "Considerava-me, inicialmente, como provido de rosto, mãos, braços e toda essa máquina composta de ossos e carne, tal como ela aparece em um cadáver, a qual eu designava pelo nome de corpo" (Descartes, 1641/1983, p. 93, grifos acrescentados). Lacan endossa inteiramente essa posição, exprimindo-a verbatim por vezes, inclusive fazendo um jogo de palavras entre corpo (corps) e cadáver (corpse): "Quem não conhece o ponto crítico pelo qual nós datamos, no homem, o ser falante: a sepultura, ou seja, aquilo pelo qual se afirma de uma espécie que, ao contrário de qualquer outra, o corpo morto nela preserva o que, quando vivo, lhe fornecia seu caráter: corpo [corps]. Permanece cadáver [corpse], não se torna carniça o corpo [corps] que a fala habitava, que a linguagem cadaverizava [corpsifiait]" (Lacan, 1970, p. 61).
} 
espírito" 8 é uma expressão clássica dessa ideia, que é retomada por Kojève em seus seminários. Ou seja, o nascimento do espírito, o aparecimento de um ser autoconsciente no mundo, tem como condição a destruição ou a consumpção da vida animal.

Esses são os pressupostos, então, da noção de intersubjetividade que se aplicou à psicanálise como antídoto ao suposto objetivismo freudiano.

\section{Intercorporeidade, significação e o sentido do eu.}

A questão que se pode colocar, na verdade, a partir desta introdução, é a seguinte: será que não se está fazendo muito barulho por nada ao procurar expurgar a psicanálise freudiana de seu objetivismo? Em outras palavras, será que é necessário se dar tanto trabalho para corrigir um ponto de mira freudiano que talvez não esteja tão fora de foco assim? O argumento que se propõe na continuidade é que esse suposto objetivismo do qual se procura resguardar ou depurar a psicanálise freudiana talvez simplesmente não esteja lá. Talvez a psicanálise de Freud não requeira, afinal de contas, esse ajuste de mira; talvez se esteja, por assim dizer, fazendo o paciente tomar remédio à toa quando se tenta fazer esse tipo de correção.

Podemos colocar as coisas de outro modo e considerar o pensamento de Freud através de outras lentes, desde outra perspectiva. Como as ideias de Freud apareceriam se as considerássemos de um ponto de vista diferente daquele proporcionado pela filosofia hegeliana e, sobretudo, pela sua reinterpretação kojèviana, que foi o ponto de vista adotado por Lacan, pelo menos num primeiro momento? Podemos, por exemplo, recorrer - mesmo que de maneira puramente instrumental, digamos assim -, a um conceito merleau-pontyano tal como a noção de intercorporeidade. Não se trata de entrar em todas as nuanças e

\footnotetext{
8 Mais precisamente: "Com a doença, o animal ultrapassa os limites de sua própria natureza; mas a doença do animal é o vir-a-ser do espírito" (Hegel, 1932/1975, p. 259-60).
} 
implicações desse conceito, mas apenas partir do sentido geral dessa ideia. Quando Merleau-Ponty introduz essa ideia de intercorporeidade, ou seja, quando ele começa a falar de intersubjetividade como intercorporeidade, uma das razões para fazer isso é tentar escapar de uma concepção excessivamente idealista de intersubjetividade, tal como exemplificada - aliás, de maneira bastante exemplar - por essa ideia examinada acima, segundo a qual os sujeitos que interagem e que, interagindo, se constituem reciprocamente sejam puras consciências, pelo menos naquilo que os torna propriamente sujeitos. Em outras palavras, que eles sejam, quanto a isso, puros sujeitos do conhecimento (ou do "reconhecimento"), do desejo ou de outro ato intencional qualquer.

Embora essa ideia já estivesse mais ou menos implícita em suas reflexões anteriores, Merleau-Ponty introduz formalmente o conceito de intercorporeidade em seu ensaio de 1959, dedicado a Husserl, "O filósofo e sua sombra", claramente como uma alternativa a uma visão idealista da intersubjetividade. Vale a pena citar na integra a passagem relevante, pois ela fornece elementos interessantes para a compreensão da abordagem freudiana que se discutirá a seguir:

\footnotetext{
Minha mão direita assistia ao surgimento do tato ativo em minha mão esquerda. Não é de maneira diversa que o corpo do outro se anima diante de mim quando aperto a mão de outro homem, ou quando o olho somente. Aprendendo que meu corpo é "coisa senciente", que é excitável - ele e não somente minha "consciência" -, preparei-me para compreender que há outros animalia e, possivelmente, outros homens. É preciso notar bem que nisto não há comparação, nem analogia, nem projeção ou introjeção. Se, apertando a mão de outro homem, tenho a evidência de seu ser-aí, é porque ela se coloca no lugar de minha mão esquerda. No aperto de mãos, meu corpo anexa o corpo de outro numa "espécie de reflexão", cuja sede, paradoxalmente, é ele próprio. Minhas duas mãos são "co-presentes" ou "co-existem", porque são as mãos de um só corpo; o outro aparece por extensão dessa co-presença. Ele e eu somos os órgãos de uma só intercorporeidade. (...) Percebo, primeiro, outra "sensibilidade" e, somente a partir daí, outro homem e outro pensamento. (Merleau-Ponty, 1960, p. 212-213, grifos nossos)
} 
A ideia de intercorporeidade ${ }^{9}$, portanto, embora preservando esse elemento de uma relação constitutiva necessária com o outro, procura preservar o fato de que esses sujeitos sejam, antes de tudo, seres corpóreos, de que a humanidade não pode acontecer ou advir senão no âmbito de um corpo vivo. Esse corpo não é apenas algo a ser ultrapassado, negado, superado ou neutralizado, mas sim um agente indispensável do próprio processo de humanização. Essa noção enfatiza, assim, a necessidade e o caráter incontornável de um corpo que não esteja apenas vivo no sentido biológico da palavra (respirando, se alimentando e sendo a sede de processos metabólicos), mas, acima de tudo, que esteja vivo no sentido fenomenológico do termo, a saber, no sentido de ser vivido, experienciado como tal. Desde essa perspectiva, portanto, quando dois sujeitos ou candidatos a sujeitos humanos se encontram, são, antes de tudo, dois corpos que se encontram, lutam, se desejam mutuamente, se tocam e se esforçam por impor ou fazer reconhecer um ao outro seus desejos. Mais precisamente, repensar a ideia de uma intersubjetividade constitutiva a partir da noção de intercorporeidade - e, portanto, da ideia de que o sujeito é originariamente encarnado (embodied) - implica que esses corpos que se encontram passem a ser vividos como corpos próprios (corpos fenomenais, experienciado como tais) apenas nesse e a partir desse encontro. Trata-se, em outras palavras, de avançar a ideia de que uma experiência corporal compartilhada é indispensável no processo de constituição do mundo humano e do sujeito humano como um ser que o vivencia $e$ age nesse mundo. $\mathrm{O}$ mundo humano não pode nascer

\footnotetext{
9 Como não é possível desenvolver mais longamente aqui esse importante conceito, contentemo-nos com uma definição sucinta, que expressa bem como este preserva o essencial da ideia de intersubjetividade (como constitutiva da subjetividade e da identidade do sujeito) sem prescindir da referência ao corpo: "Esse Ineinander [envolvimento; "ser um no outro"] é uma 'intercorporeidade' de percepção, de linguagem, de práxis, que não deve ser compreendida como um vínculo entre corpos animados existindo primeiro cada um para si, mas antes como um co-nascimento [conaissance, "co-nhecimento"] dos corpos animados em um tecido carnal em que eles sejam diferença para si de uma única carne" (Dupond, 2008, p. 116). Para uma discussão da utilização desse conceito em psicanálise, tanto de um ponto de vista teórico quanto clínico, ver Coelho (2003).
} 
daquela maneira desencarnada que uma concepção mais idealista da subjetividade poderia fazer crer.

Por que falar, então, de intersubjetividade e intercorporeidade na obra inicial de Freud, como propõe o título deste trabalho? Mais precisamente, por que colocar essa questão especificamente a respeito de sua obra inicial, isto é, de seus primeiros trabalhos? De acordo com essa interpretação objetivista de Freud da qual partimos, aquela que exigiria o recurso à noção de intersubjetividade como fator de correção, de onde viria esse suposto objetivismo de Freud? A resposta mais usual a essa pergunta aponta para o compromisso de Freud com certa epistemologia naturalista, realista e objetivista. Freud teria um compromisso originário, decorrente de sua formação médica e científica, com uma visão de ciência que o teria inicialmente comprometido com essa epistemologia objetivista, com uma concepção que se poderia designar como realismo científico do objeto. Essa concepção seria própria do tipo de ciência que ele aprendera inicialmente e, portanto, sua influência teria sido tanto mais marcante quanto mais Freud estivesse ainda próximo de sua educação científica, de sua formação médica, ou seja, em seus primeiros trabalhos. Verossimilmente, o jovem Freud teria sido mais afetado por essa epistemologia do que o Freud maduro, que já teria tido mais tempo para pensar, refletir e escapar das amarras daquela concepção de ciência, o que lhe teria, aliás, permitido pensar todas aquelas coisas novas e originais, cuja originalidade é justamente o que seria preciso destacar pelo recurso à noção de intersubjetividade, entre outras.

Diante desse quadro, trata-se de tentar mostrar que, mesmo nesse primeiro Freud, mesmo nesse momento inicial que teria tudo para ser o mais objetivista de todos os estágios do percurso de seu pensamento, uma ideia muito próxima a essa noção merleau-pontyana de intercorporeidade pode ser identificada ou, em todo caso, um conjunto de formulações que poderia ser interpretado dessa maneira, utilizandose essa noção como chave de leitura. Dessa maneira, já estaria presente em Freud, na origem mesma do processo de fundação da psicanálise, 
uma concepção bastante sofisticada de intersubjetividade como intercorporeidade. Não se trataria, assim, daquele objetivismo rasteiro, mas antes da ideia de que o sujeito psíquico, o sujeito de qualquer ato intencional - o sujeito do desejo, do juízo, do pensamento, da consciência - se constituiria numa relação inescapável com seus outros. Mas essa relação constitutiva com o outro não é concebida de acordo o modelo idealista e desencarnado de intersubjetividade de que se falou acima, mas sim como uma relação antes de tudo intercorpórea, num sentido semelhante ou próximo, pelo menos em termos gerais, do que Merleau-Ponty chamou de intercorporeidade. Ou seja, quando um sujeito ou um ser em vias de se constituir como sujeito se coloca diante de outro ser humano e ascende à condição de sujeito nesse e através desse encontro, todos os envolvidos comparecem nesse encontro primordialmente como corpos, e nunca como consciências puras, cuja ação e experiência possam ser concebidas sem referência à sua corporeidade. Ao contrário, o próprio fenômeno da consciência teria que ser pensado como algo que pode acontecer nesses corpos a partir do momento que o encontro com o corpo do outro torna possivel o advento de um sujeito.

Questões como identidade e significação são, de fato, intensamente trabalhadas por Freud em seus primeiros trabalhos, ou seja, o problema da construção do sentido do eu e, por extensão, da gênese da significação em geral. Na verdade, essas duas questões estão profundamente interligadas, a ponto de se poder afirmar que se trata de dois aspectos de uma mesma questão. É possível mostrar, além disso, que o tratamento dessas questões se dá inteiramente no contexto de uma concepção da intersubjetividade como intercorporeidade, e não segundo os parâmetros de um objetivismo que precisaria ser remediado a partir de fora, pela introdução de conceitos originariamente alheios à inspiração freudiana. Se for possivel, então, mostrar que essas questões são trabalhadas nesses termos - de forma, aliás, bastante explícita, diga-se de passagem - já nesse primeiro momento da teorização freudiana (em que o seu objetivismo estaria supostamente mais 
presente e teria sido mais intenso), isso forneceria um argumento bastante convincente de que há uma concepção bastante sofisticada de intersubjetividade em Freud desde o princípio e que talvez não fosse necessário jogar fora o bebê da corporeidade junto com a água do banho do objetivismo, a fim de consertar esse aspecto supostamente deficiente de seu pensamento.

Trata-se aqui apenas de introduzir rapidamente essas questões (identidade e significação), para depois comentar brevemente algumas passagens de um texto pertencente a esse momento inicial da obra de Freud, a fim de ilustrar como se articula aí a sua concepção de intersubjetividade. Com relação à questão da significação, o suposto objetivismo de Freud o teria comprometido com uma visão ingênua sobre o problema da origem da significação. Em linhas gerais, segundo essa leitura que atribui uma atitude objetivista a Freud, a significação surgiria inicialmente por uma operação de nomeação, ou seja, o universo da significação começaria a tomar forma a partir do momento em que se atribuíssem nomes às coisas, em que palavras e objetos de associassem uns aos outros na mente e na experiência dos sujeitos (Gabbi, 2005). Essa concepção estaria articulada em uma de suas primeiras obras: o ensaio crítico que Freud publica sobre as afasias em 1891. Sendo a afasia um distúrbio da fala ou da compreensão da fala causado por lesão cerebral, não é surpreendente que, no plano teórico, a questão da linguagem e da significação apareça ali numa posição de destaque. Ao final desse ensaio, Freud (1891/1992) elabora um esquema para sintetizar suas conclusões, em que apresenta a ideia (ou representação) de palavra como formada por certo tipo de material sensorial organizado de determinada maneira: basicamente, a impressão acústica da palavra ouvida, a imagem mental e cerebral dos movimentos musculares para a articulação da fala (imagem cinestésica da fala) e, mais tarde, as imagens visuais da leitura e as imagens de movimento da escrita. Todo esse material sensorial se associaria, então, para formar o que, do ponto de vista psicológico, aparece como uma palavra ou uma ideia de palavra (Wortvorstellung). Mas como essa ideia 
de palavra ganha sentido? - pergunta-se Freud. Afinal, a linguagem é, antes de tudo, um instrumento simbólico para produzir ou expressar significações. Sua resposta, nesse momento, é que a palavra se reveste, originariamente, de um sentido ao se associar com uma ideia ou representação de objeto (Objektvorstellung). Esta, por sua vez, seria formada por outro conjunto das mais variadas impressões sensoriais e se associaria, normalmente, com a ideia de palavra a partir de seu componente visual (a imagem visual do objeto, como diz Freud), o que se evidencia no fato de que a criança aprende a falar, inicialmente, associando as configurações sonoras que aprendeu a reconhecer como palavras a objetos que percebe pela visão (quando aponta e pergunta o nome de alguma coisa, por exemplo). Estaria aí a prova, dizem os críticos e comentadores de Freud, de que ele pensa a origem da significação como resultando de uma operação primordial de nomeação. Essa interpretação da teoria freudiana da significação da linguagem, claramente, converge - e ofereceria uma das evidências mais contundentes - com objetivismo que muitos críticos atribuem a Freud e que requereria o recurso à noção de intersubjetividade para ser corrigido, como se discutiu acima. Ou seja, esse objetivismo se manifestaria exemplarmente na concepção freudiana da linguagem, segundo a qual a significação teria uma origem perfeitamente extralinguística: ela proviria de um objeto externo ao sujeito e externo à linguagem, subsistindo e podendo ser concebido independentemente de sua relação com ambos, que, ao se associar contingentemente com uma ideia de palavra, lhe confere significação. Há várias evidências em Freud que permitem rebater esse tipo de crítica $^{10}$, mas apenas uma delas será discutida aqui, já pode nos conduzir mais diretamente à maneira como uma ideia de intersubjetividade como intercorporeidade aparece no primeiro Freud.

10 Para uma crítica dessa interpretação nominalista da teoria freudiana da significação, ver Caropreso e Simanke (2006), Simanke (2010) e Simanke (2016b). 
Para dizê-lo resumidamente, essa ideia de que a palavra ganha sentido ao se associar com o objeto só implicaria alguma espécie de objetivismo, se Freud estivesse assumindo que a ideia de objeto tem sentido por si só ou que recebe inteiramente seu sentido de um objeto real externo que, por sua vez, fosse intrinsecamente significativo ou capaz de gerar significação. Em outras palavras, esse objetivismo só se justificaria se Freud considerasse a questão da significação do objeto como absolutamente não problemática, como não requerendo maiores elucidações. Contudo, embora Freud, de fato, não aborde o problema da significação do objeto em seu estudo sobre as afasias, ele o faz num texto um pouco posterior, no seu famoso manuscrito de 1895, o Projeto de uma psicologia (Freud, 1950/1987). Ai ele se faz exatamente essa pergunta: de onde o objeto retira a sua significação? E a resposta que ele fornece vai envolver todo um complexo jogo envolvendo percepção de objetos externos e sensações corporais - inclusive, desempenhando um papel central nesse processo, as sensações envolvidas na relação com um tipo bastante particular de objeto externo, que é o semelhante, o "próximo" (Nebenmensch), como Freud diz, isto é, outro ser humano. O que está em questão nessas passagens não é apenas a constituição de um campo de objetos como entidades dotadas de sentido - sentido que, como vimos acima, se propagaria, de alguma maneira, às palavras que os designam -, mas também a constituição concomitante da própria identidade do indivíduo, daquilo que podemos designar como o sentido do eu. Há várias etapas nesse processo. Freud está basicamente falando de operações cognitivas, organizadas em torno desse tema central que é a questão do juízo, isto é, a operação pela qual o sujeito do conhecimento tira conclusões a respeito das coisas e se torna capaz de atribuir-lhes existência e \ou determinadas propriedades e, ao fim e ao cabo, fazer afirmações a respeito delas. Esse é o contexto em que o problema da intersubjetividade como intercorporeidade aparece trabalhado nesse primeiro momento.

O que é julgar, para Freud? Para dar, nesse momento, uma definição bastante abreviada, pode-se dizer que o juízo, para ele, consiste na 
operação pela qual se distinguem os atributos permanentes e os atributos variáveis de uma entidade, ou seja, pela qual se distingue entre coisa e predicado. Embora essa seja uma operação cognitivamente sofisticada, Freud procura abordá-la nos seus primórdios, no momento mesmo da formação de uma primeira relação entre o organismo e o mundo que, do ponto de vista merleau-pontyano mencionado acima, poderiamos designar como um estágio pré-reflexivo da experiência. Como, então, nessas condições se pode distinguir entre coisa e predicado? Talvez a melhor maneira de prosseguir aqui seja apresentar algumas passagens cruciais do texto freudiano e comentá-las a seguir.

A primeira etapa do argumento de Freud é introduzir o conceito de juizo. Para ele, o reconhecimento de objetos externos está sempre a serviço da busca de um reencontro com o objeto percebido quando de uma experiência primordial de satisfação (o seio materno, no caso da fome do recém-nascido, por exemplo) para então tornar a realizar ação anteriormente bem sucedida em aplacar o desprazer da necessidade (a sucção do seio, nesse caso). O problema é que o objeto percebido, em sua representação neural, sempre se apresenta como um complexo, nunca como algo simples: uma pluralidade de neurônios tem que ser ocupada pela excitação nervosa para constituir esse complexo perceptivo. Como resultado, o problema da identidade entre duas percepções - ou, mais precisamente, entre uma percepção atual e a memória de uma percepção anterior - nunca é uma questão de tudo ou nada, nunca ou muito raramente dá-se como uma alternativa entre uma coincidência total e uma discordância absoluta. Muito mais frequentemente, tratar-se-á de uma concordância apenas parcial. Freud esquematiza isso da maneira mais simplificada possivel, pensando uma relação entre dois complexos neuronais constituídos por dois neurônios cada, mas tendo um neurônio em comum. Nesse exemplo, o complexo neuronal correspondendo à percepção do objeto da experiência original de satisfação seria formado pelos neurônios " $a$ " e "b" (complexo " $a+b$ "), enquanto que a percepção atual corresponderia ao complexo "a+c". O problema de reencontrar o objeto em cuja presença a ação mereça ser 
executada se define, portanto, como o problema de como, a partir do complexo "a+c", reencontrar o complexo "a+b". Freud analisa aqui, portanto, especificamente o caso em que:

(...) a ocupação de desejo [Wunschbesetzung] está presente e, junto a ela, uma percepção que não se harmoniza totalmente com ela, mas apenas em parte. Já é tempo, porém, de lembrar que as ocupações de percepção [Wahrnehmungbesetzungen] nunca são ocupações de neurônios isolados, mas sempre de complexos. Até aqui descuidamos dessa característica, [mas] agora é hora de levá-la em conta. Em termos gerais, a ocupação de desejo alcança [o complexo formado pelo] neurônio "a" + neurônio "b"; as ocupações de percepção [alcançam o complexo formado pelo] neurônio "a" + neurônio "c". Como esse deve ser o caso mais frequente, mais ainda que o de identidade, ele exige uma ponderação mais exata. (Freud, 1950/1987, p. 423)

A partir dessa situação, Freud descreve o surgimento do juizo como uma estratégia para passar dessa coincidência parcial para uma coincidência que justifique a possibilidade de que a ação seja bemsucedida. A "experiência biológica”, diz ele, ensina o agente a suspender a execução da ação até que a proximidade entre os dois complexos possa ser aperfeiçoada. Falar de uma coincidência parcial, por sua vez, implica reconhecer que há sempre uma parte do complexo que permanece constante e que sempre está presente (o neurônio "a" no exemplo dado por Freud) e outra que varia e que pode estar presente ou não (os neurônios "b” e “c”). Julgar consistirá, então, em aprender a reconhecer a diferença entre essas duas espécies de componentes dos objetos percebidos ou representados, por um lado; por outro lado, distinguir a semelhança entre a parte constante dos objetos e o "núcleo do eu" - a representação do corpo que constitui a parte constante da representação de si mesmo que se constrói no psiquismo -, assim como a semelhança entre as partes variáveis dos objetos e do eu, que são processadas pelo mesmo sistema do aparelho neuronal11. Por fim, a

${ }^{11}$ Freud antes distinguira como partes do sistema " $p s i$ " o sistema responsável pela memória e pelos processos propriamente psíquicos do aparelho neuronal - dois subsistemas: o núcleo, que registra os processos que ocorrem no interior do organismo, e o manto, em que se representam os objetos e acontecimentos do mundo externo. O núcleo de " $p s i$ " coincidirá com o núcleo do eu, o fundamento corporal da identidade. No manto, são representadas as percepções externas que o sujeito pode, 
linguagem encontrará nomes para as operações e distinções resultantes desse aprendizado e uma "teoria do juízo" pode assim tomar forma:

\begin{abstract}
O complexo perceptivo se decomporá, na comparação com outros complexos perceptivos, num componente "neurônio a" - aquele que, justamente, na maioria das vezes, permanece idêntico - e um segundo componente, o "neurônio b", que quase sempre varia. Depois a linguagem encontrará para essa decomposição o termo juizo [Urteil] e distinguirá a semelhança que, de fato, existe entre o núcleo do eu [Kern des Ich] e o componente constante da percepção [por um lado], e entre as ocupações variáveis dentro do manto e o componente inconstante [por outro]; o neurônio "a" será denominado coisa $[$ Ding], e o neurônio "b", sua atividade ou propriedade - em suma, seu predicado [Prädikat]. (Freud, 1950/1987, p. 423, grifos do autor)
\end{abstract}

A linguagem expressa, portanto, essas características primordiais e pré-reflexivas do julgar: "Urteil" significa, etimologicamente, "parte primordial" ou "partição primordial", aludindo, para Freud, ao fato de que o juízo começa como uma operação de decomposição dos complexos perceptivos dos objetos. A relação de semelhança estabelecida pelo juízo entre a coisa e o núcleo do eu já introduz um elemento de corporeidade no processo, uma vez que o núcleo do eu é constituído, basicamente, pela representação mental e cerebral das afecções corporais. Mas o aspecto propriamente intercorporal do processo se explicita a seguir, quando Freud descreve o que considera ser a situação prototípica pela qual se dá esse juízo primordial. Trata-se, em suma, de explicar como se obtém a passagem da coincidência parcial para a coincidência total entre os dois complexos. É esse trabalho que Freud define, nesse momento, como pensamento. Mas não se trata, evidentemente, de uma forma reflexiva de pensar. Ao contrário, o pensamento, nesse estágio, é pensado fundamentalmente como ação, tanto no sentido da ocupação neural de representações ou imagens de movimento, quanto no de efetiva execução de movimentos corporais orientados, isto é, não reflexos ou aleatórios, mas guiados por uma meta. Não seria exagero

alternativamente, experienciar como pertencentes a si ou não; por isso, tanto as representações de objeto quanto aquilo a que Freud se refere como "as partes variáveis do eu" é concebido como sendo processado no manto do sistema " $p s i$ ". 
afirmar que Freud trabalha aqui com uma noção implícita de intencionalidade corporal, que não estaria em desacordo com as abordagens fenomenológicas do corpo. Com efeito, ele afirma:

\begin{abstract}
Pode-se continuar a analisar esse processo: si o neurônio "a" concorda, mas é percebido o neurônio "c" em vez do neurônio "b", o trabalho do eu segue as conexões desse neurônio "c" e, através de um fluxo de Qn [quantidade de excitação nervosa] ao longo dessas conexões, faz emergir novas ocupações, até encontrar um acesso ao neurônio "b" faltante. Como regra geral, obtém-se uma imagem de movimento [Bewegungsbild] que se interpõe entre o neurônio "c" e o neurônio "b" e, com a reanimação dessa imagem através de um movimento [Bewegung] efetivamente executado, se estabelece a percepção do neurônio "b" e, com isso, a identidade buscada. (Freud, 1950/1987, p. 423-4)
\end{abstract}

Essa descrição abstrata fica mais clara com o exemplo fornecido a seguir, em que o aspecto intercorporal se torna também mais evidente:

Por exemplo: a imagem mnêmica desejada [pela criança] é a imagem do seio materno e seu mamilo em visão frontal, e a primeira percepção é uma visão lateral desse objeto, sem o mamilo. Na lembrança da criança, encontra-se uma experiência [Erfahrung], ocorrida por acaso ao mamar: a de que, com um determinado movimento da cabeça [Kopfbewegung], a imagem frontal se transforma em imagem lateral. A imagem lateral que se vê agora leva ao movimento de cabeça [Kopfbewegung]: uma tentativa mostra que o seu inverso recíproco tenha que ser executado e se obtém a percepção da visão frontal. (Freud, 1950/1987, p. 424)

Ou seja, o que Freud chama de juizo, na sua forma mais primitiva, é uma interação corporal entre a mãe e o recém-nascido, em que percepções visuais (a visão lateral e frontal do seio materno), movimentos (laterais da cabeça, nesse caso) e sensações corpóreas (o contato da face com a pele da mãe, por exemplo) se compõem numa experiência que culmina na obtenção da satisfação desejada. O conjunto dessa experiência é designado, então, como pensar e julgar.

Mas esse fator de intercorporeidade se torna ainda mais explícito e, ao mesmo tempo, mais central no argumento freudiano nos desdobramentos imediatamente posteriores dessa concepção do juízo, quando Freud vai considerar a relação do sujeito em formação, não mais com um objeto qualquer, com uma parte do corpo do outro em particular (um "objeto parcial" no linguajar kleiniano; um objeto " $a$ ", 
caso se prefira a expressão lacaniana), mas com a figura do outro enquanto tal, isto é, enquanto totalidade. Essa figura aparece representada, na terminologia do Projeto, pelo Nebenmensch literalmente, o ser humano adjacente ou contíguo a si, mais comumente traduzido como o "próximo" e que desempenha mais ou menos a mesma função da forma substantiva do outro nos discursos sobre a intersubjetividade. $O$ interessante é que essa abordagem bastante precoce da intersubjetividade em Freud é formulada, muito claramente, desde a perspectiva de uma intercorporeidade. A relação constitutiva com o outro, tal como Freud a concebe, é essencialmente uma relação intercorporal - e ela é constitutiva tanto no sentido de constituição do campo dos objetos, quanto no de constituição do sentido do eu e da própria identidade do sujeito.

Em suma, trata-se, para Freud, de aplicar essa concepção geral do juízo, tal como apresentada acima, ao caso particular, mais crucial, da relação com o semelhante. Cabe citar mais longamente aqui, na integra, a passagem relevante, para depois comentá-la. Diz Freud:

\begin{abstract}
Suponhamos agora que o objeto fornecido pela percepção seja semelhante ao sujeito, isto é, um próximo [Nebenmensch]. Nesse caso, o interesse teórico ${ }^{12}$ se explica, sem dúvida, pelo fato de que um objeto como este seja simultaneamente o primeiro objeto de satisfação e o primeiro objeto hostil, assim como o único poder auxiliar. Com relação ao próximo [Nebenmensch], portanto, o ser humano aprende a reconhecer. É que os complexos perceptivos que provenham do próximo serão, em parte, novos e incomparáveis - por exemplo, seus traços [faciais] no âmbito visual; ao contrário, outras percepções visuais - por exemplo, o movimento de suas mãos [Handbewegungen] - coincidirão, no sujeito, com a lembrança de impressões visuais próprias, totalmente semelhantes, de seu corpo próprio [eigenen Körper], com as quais as lembranças de movimentos vivenciados [erlebten Bewegung] por ele mesmo se encontram associadas. Outras percepções de objeto, além disso - por exemplo, se ele [o próximo] grita despertarão a lembrança do próprio grito e, com isso, de vivências de dor
\end{abstract}

\footnotetext{
12 No Projeto, Freud chama de pensamento teórico, em oposição ao pensar prático ou recognitivo, a exploração de objetos não imediatamente relacionados com uma experiência prévia de satisfação. "Teórico", portanto, designa apenas uma relação mais distante dessa forma de pensar - sempre entendida como ocupação neural de representações de movimento e \ou execução concomitante dos movimentos correspondentes - com a meta da restauração da identidade entre percepção e lembrança e da realização do desejo.
} 
próprias. E, assim, o complexo do próximo se separa em dois componentes, um dos quais se impõe por uma conjunção constante e se mantém reunido como uma coisa, enquanto que o outro é compreendido [verstanden] por um trabalho mnêmico, isto é, pode ser reconduzido a uma notícia do corpo próprio [eigenen Körper]. A essa decomposição de um complexo perceptivo se chama seu reconhecimento; ela contém um juízo e encontra seu término quando este último alcança sua meta. (Freud, $1950 / 1987$, p. 426-7, grifos nossos)

De que fala Freud nessa passagem? Antes de tudo, trata-se de aplicar sua concepção geral do juízo e do pensamento à relação do sujeito com o outro ou semelhante. Essa situação, no entanto, traz consigo certas peculiaridades, devidas ao fato mesmo de o objeto em questão ser semelhante ao corpo próprio (o fundamento do juízo e do pensar, como vimos acima). Essa figura do próximo ou semelhante representa a parte constante das diversas experiências perceptivas do sujeito em formação com relação a ela - o neurônio "a" (a coisa), por assim dizer, na esquematização freudiana anterior. Mas agora as partes variáveis (os neurônios "b" e "c" do exemplo anterior, os predicados da coisa) assumem a forma crucial da satisfação ou desejo e da hostilidade. Por isso, as duas predicações fundamentais do próximo se dão enquanto objeto de desejo e enquanto objeto hostil, conforme sua percepção tenha estado relacionada a uma experiência de satisfação (Befriedigungserlebnis) ou a uma experiência de dor (Schmerzerlebnis), respectivamente. Como se viu acima, a exploração do objeto pelo pensamento (entendido como ação) tem consequências para a construção do sentido de identidade do eu, já que o juízo apreenderá a semelhança entre as partes constantes da percepção do objeto (a coisa) e a parte constante da experiência corporal de si (o núcleo do eu). Essas consequências se acentuam e, ao mesmo tempo, se tornam mais problemáticas agora, quando o objeto em questão é um ser semelhante a si - fundamentalmente, um corpo alheio comparável, pelo menos em parte, ao corpo próprio. A questão agora, portanto, é: como discernir entre o eu e o outro? Como distinguir, na experiência perceptiva, entre aquilo que pode ser considerado próprio e o que pode ser considerado alheio? A resposta de Freud aponta, mais uma vez, para a experiência 
corporal compartilhada com esse outro. Em seu exemplo, há uma diferença crucial entre tocar e ver a mão do outro e tocar e ver a própria mão. No primeiro caso, trata-se sempre da percepção (tátil ou visual) de um objeto externo, que não se vincula a uma experiência corporal própria. O sujeito ainda poderia ver a sua própria mão imóvel como um objeto e compará-la à percepção visual da mão do outro, ou seja, perceber visualmente sua mão como um objeto. Mas quando toca sua própria mão, ele ingressa num outro universo sensorial. À percepção visual agora se associam outras sensações provenientes do próprio corpo e não pertencentes ao universo da percepção externa: ele pode sentir-se tocar e sentindo-se realizando os movimentos do tocar, pode sentir a própria mão sendo tocada, e não apenas tocando um objeto alheio a si; ele pode associar, através dessas sensações, o ato perceptivo a todo um mundo de sensações corpóreas que podem ser experimentadas mesmo quando ele não se encontra engajado na exploração do mundo. No mesmo ato em que aprende a distinguir entre a coisa e os predicados do outro, o indivíduo constrói uma experiência de si como distinto desse outro, a partir de um estado inicial de indiferenciação (como saber a quem pertence a mão originalmente percebida?), num sentido bastante próximo ao Ineinander merleaupontyano mencionado acima. Não estamos, portanto, diante de uma situação em que um sujeito e um objeto previamente constituídos e diferenciados se defrontam num processo cognitivo (o sujeito conhecendo o objeto enquanto tal, como se esperaria de uma posição objetivista diante do problema do conhecimento), mas de uma experiência intercorporal em que o indivíduo explora (tátil e visualmente no exemplo freudiano) seu próprio corpo e o corpo do outro - explora o corpo do outro a partir da exploração do corpo próprio e o corpo próprio a partir da exploração do corpo do outro. Podemos lembrar aqui a insistência com que Merleau-Ponty recorre ao exemplo das mãos que se tocam uma à outra, à reversibilidade do tocar e ser tocado que caracteriza esse ato, para ilustrar suas concepções sobre a experiência do corpo e suas implicações, tanto no plano fenomenológico quanto 
ontológico. Nessa experiência, o sujeito se constitui como sujeito no mesmo movimento em que constitui o outro como objeto, predicando-o como desejável ou hostil, mas, ao mesmo tempo, como outro sujeito que se apresenta a si (comparável, diz Freud) e que se coloca também como agente de uma maneira decisiva. Por exemplo, ele pode agir como auxiliar externo, como aquele outro sujeito que é capaz de realizar, no lugar organismo infantil indefeso e desamparado, as ações sobre o mundo indispensáveis à obtenção da satisfação, à realização do desejo e à fuga da dor - numa palavra, à própria sobrevivência. É, enfim, nessa espécie de dança primordial dos corpos entrelaçados que sujeito e objeto se constituem: eles não preexistem ao processo.

Além disso, encontra-se nessa passagem a ideia de que a compreensão do objeto - a apreensão de seu significado - depende dessa capacidade de vinculá-lo a uma experiência corporal. Com isso, encontram-se pelo menos relativizadas em grande medida as conotações objetivistas de suas concepções sobre a linguagem, tal como apresentadas em seu ensaio sobre as afasias (Freud, 1891/1992): se a linguagem recebe o seu sentido do objeto, este, por sua vez, ganha sentido a partir do seu vínculo com as vivências do corpo, de maneira que, em última instância, o problema da significação como um todo é reconduzido a essa intercorporeidade originária. Não é à toa que Freud relaciona a emergência de certas formulações da linguagem a esses processos primitivos de julgar e pensar. Ele o faz novamente em diversas passagens do texto, que não temos espaço aqui para explorar. Esse vínculo entre linguagem, corpo e significação reaparece ainda em sua obra bem posterior, como atestado, por exemplo, por suas elaborações em torno da linguagem de órgão esquizofrênica em seus artigos metapsicológicos de 1915 (Caropreso \& Simanke, 2006).

Essa importância da corporeidade (e da intercorporeidade) na teoria freudiana do juízo é mais do que reiterada na sequência do texto. Ele diz, por exemplo:

Portanto, o julgar, que depois passa a ser um meio para reconhecer o objeto que talvez tenha adquirido uma importância prática, é 
originariamente um processo associativo entre ocupações que vêm de fora e ocupações provenientes do corpo próprio [von eigenen Körper stammenden Besetzungen], uma identificação entre notícias ou ocupações em "phi"13 e de dentro. (Freud, 1950/1987, p. 428-9, grifos nossos] ${ }^{14}$

Em suma, se há uma teoria do pensamento, do juízo e da cognição em Freud, é uma teoria que vê esses processos como acontecimentos inerentemente encarnados (embodied), e não como atos de sujeitos que se definam como "consciências puras", tal como ocorre no âmbito de uma concepção idealista da intersubjetividade.

\section{A presença do outro no eu.}

Para concluir, cabe apenas retomar e comentar rapidamente uma passagem clássica e muito comentada desse mesmo texto, o Projeto de uma psicologia, em que Freud, pela primeira vez define sua concepção de desejo, para mostrar como essa mesma ideia de uma intersubjetividade se faz aí presente (ao contrário da interpretação objetivista), mas sempre como uma relação entre sujeitos essencialmente encarnados - ou seja, a ideia de uma intersubjetividade como intercorporeidade.

Como se sabe, a famosa definição de desejo apresentada na seção C do capítulo 7 de A interpretação dos sonhos (Freud, 1900/1982a) encontra-se claramente prefigurada na seção do Projeto dedicada ao tema da vivência de satisfação (Befriedigungserlebnis) e suas consequências psíquicas. É interessante observar que um tema tradicional da antropologia filosófica - o desamparo (Hilflosigkeit) inicial do indivíduo humano e suas consequências existenciais - é abordado explicitamente por Freud nessa passagem, dentro de um contexto inteiramente voltado, como é sempre o caso no texto do Projeto, para

13 "Phi" designa, no Projeto, o sistema neuronal voltado para a recepção dos estímulos sensoriais provenientes do mundo externo.

${ }^{14}$ Apenas para dar mais um exemplo: "A respeito do julgar, cabe observar ainda mais que seu fundamento é, evidentemente, a preexistência de experiências corporais, sensações $e$ imagens de movimento próprias [eigenen Körpererfahrungen, Empfindungen und Bewegungsbildern]" (Freud, 1950/1987, p. 428, grifos nossos). 
uma reconstrução especulativa dos mecanismos neurais envolvidos. Freud observa que o núcleo do sistema " $p s i$ ", que recebe as quantidades de excitação nervosa oriundas do interior do organismo, ao ser preenchido além de certo limite, busca a descarga dessas quantidades, seguindo a tendência geral do aparelho neuronal para manter essas quantidades no nivel mais baixo possivel (o que Freud denominou "princípio de constância"). Contudo, o recém-nascido não tem outra via de descarga à sua disposição a não ser ações reflexas (choro, agitação dos membros) e alterações fisiológicas internas (alterações vasculares, secreções glandulares). Essas ações, no entanto, são incapazes de fazer cessar a recepção de quantidade endógena. No caso paradigmático da fome do recém-nascido utilizado aqui, a supressão dessa recepção requer uma ação complexa e orientada a fins, que precisa ser executada sobre o ambiente, ou seja, o que Freud, nas primeiras páginas do texto havia definido como ação específica - nesse caso, a obtenção de alimento. A incapacidade do recém-nascido para realizar por si só essa ação é o que caracteriza o seu desamparo e requer a intervenção de algum auxilio externo, o que acarreta toda uma importante série de consequências:

Aqui, a supressão do estímulo somente é possível através de uma intervenção que elimine por certo tempo, no interior do corpo, a liberação de $Q n$ [quantidade de excitação nervosa], e esta exige uma alteração do mundo exterior (provisão de alimento, aproximação do objeto sexual) que, como ação específica, só se pode produzir por caminhos definidos. O organismo humano é, a princípio, incapaz de realizar a ação específica. Esta sobrevém através de um auxílio alheio: pela descarga através da alteração interior [por exemplo, o choro reflexo do recém-nascido], um indivíduo experiente dá-se conta do estado da criança. Essa via de descarga adquire, assim, a função secundária, extremamente importante, de comunicação [Verständigung], e o desamparo [Hilflosigkeit] inicial do ser humano é a fonte primordial de todos os motivos morais [die Urquelle aller moralischen Motive]. (Freud, 1950/1987, p. 410-1, grifos do autor)

O que exatamente Freud está dizendo nessa passagem? Basicamente que, devido ao seu desampara originário, a relação com o outro é absolutamente constitutiva da realidade humana, uma vez que, para começar, ela é a condição sine qua non da própria sobrevivência 
biológica. Dizer que o desamparo é a fonte de todos os motivos morais é afirmar que o valor supremo pela qual toda a conduta humana se pautará ao longo da vida, quer esse valor seja ou não reconhecido conscientemente como tal, é o de ser amado ou desejado pelo outro, uma vez que, sem alguém que se interesse ou esteja suficientemente motivado para o cuidado (outro tema heideggeriano) do recém-nascido, a própria sobrevivência se torna impossivel. Assim, a questão do desejo do outro e seu papel constitutivo da realidade, tão cara às doutrinas da intersubjetividade, se encontra, de fato, presente em Freud desde o começo, mas num contexto teórico em que a noção mesma desejo está longe de se encaixar no modelo de uma subjetividade pura, desencarnada, em relação de ruptura com o mundo natural e, muito menos, de se definir o como "nada revelado" proposto por Kojève e incorporado por Lacan, propagando-se a partir daí para um segmento significativo do campo psicanalítico.

Há outra passagem, bastante mais tardia, de Freud, que costuma ser frequentemente citada como a expressão mais clara de uma intuição, ainda que rudimentar, da importância da intersubjetividade para a psicanálise, justificando a sua reinterpretação nesse sentido. Trata-se do parágrafo de abertura de sua obra de 1921, Psicologia das massas e análise do eu - uma obra, portanto, mais afinada, à primeira vista, como essas interpretações "culturalistas" e antinaturalistas da psicanálise, já que a traz para mais perto do campo da teoria social. Freud afirma aí:

A oposição entre psicologia individual e psicologia social ou das massas que, à primeira vista, nos parece muito substancial - perde boa parte de sua nitidez quando se a considera mais a fundo. É verdade que a psicologia individual se restringe ao ser humano singular e estuda os caminhos pelos quais este busca alcançar a satisfação de suas exigências instintivas. No entanto, muito raramente, em determinadas condições excepcionais, ela pode prescindir dos vínculos desse indivíduo com outros. $\mathrm{Na}$ vida mental do indivíduo, o outro [der andere] comparece, com total regularidade, como modelo, como objeto, como auxiliar e como inimigo e, por isso, desde o princípio, a psicologia individual é simultaneamente psicologia social, nesse sentido mais lato, mas inteiramente legitimo. (Freud, 1921/1982b, p. 65) 
Pode-se dizer com certeza que, apesar da distância e dos contextos teóricos muito distintos que as separam, o fundamento metapsicológico dessa afirmação que Freud faz em 1921 se encontra naquela descrição biológica do desamparo originário do recém-nascido, na afirmação de que esse desamparo é a fonte originária de todos os motivos morais e no desenvolvimento teórico que a sustenta. Ou seja, se é, no limite, impossivel distinguir entre a psicologia do indivíduo e a psicologia coletiva do grupo, como Freud diz em Psicologia das massas, é porque, biologicamente desamparado, o organismo humano só pode sobreviver e, sobrevivendo, tornar-se um ser humano no pleno sentido da palavra - através dessa relação incontornável e constitutiva com o outro. Mas essa não é uma relação abstrata ou ideal, mas sim uma relação absolutamente carnal com o outro, a cujo desejo, de alguma maneira, o novo ser precisa corresponder. Ele precisa ser amado e desejado pelo outro, para que não apenas sua sobrevivência biológica seja assegurada, mas também para que os parâmetros sobre o que significa ser um sujeito lhe sejam fornecidos. Em última instância, tudo que cada ser humano procura fazer durante toda sua vida é tornar-se aquilo que ele, consciente ou inconscientemente, considera que o outro deseje que ele seja. É claro que isso é impossivel de ser atingido - inclusive pelo fato de que os outros em questão são também incapazes de formular explicitamente essas exigências, até mesmo para si próprios. É por isso que, como ensina a psicanálise, há algo de neurótico em cada sujeito: devido a essa necessidade - e, ao mesmo tempo, essa impossibilidade - de cumprir ou de realizar esse ideal.

Essas observações servem apenas para sugerir que talvez não seja necessário inserir no pensamento freudiano uma ideia de intersubjetividade estrangeira à sua teoria, porque talvez já se encontre lá uma ideia como essa que, porém, não é aquela intersubjetividade das consciências puras que lutam por puro prestígio, mas - o que talvez seja mais interessante - uma intersubjetividade inteiramente corporal e carnal desde a origem que emerge em corpos que vivem e experienciam 
esse viver em si próprios e que, portanto, são organicamente sujeitos, em todos os sentidos essenciais da palavra.

\section{Referências bibliográficas:}

Caropreso, F. \& Simanke, R. T. (2006). A linguagem de órgão esquizofrênica e o problema da significação na metapsicologia freudiana. Revista de Filosofia da PUCPR, 19 (23), 106-128.

Coelho, N. (2003). Da intersubjetividade à intercorporeidade: contribuições da filosofia fenomenológica ao estudo psicológico da alteridade. Psicologia USP, 14 (1), 185-209.

Descartes, R. (1641/1983). Meditações. In G. G. Granger \& G. Lebrun (Orgs.). Descartes (Col. Os Pensadores) (pp. 73-211). São Paulo: Abril Cultural.

Descombes, V. (1979/1998). Modern French philosophy (L. Scott-Fox and J. M. Harding, Transl.). Cambridge, UK: Cambridge University Press.

Dupond, P. (2008). Dictionnaire Merleau-Ponty. Paris: Ellipses.

Freud, S. (1900/1982a). Die Traumdeutung. In A. Mitscherlich, A. Richards \& J. Strachey (Eds.). Sigmund Freud: Studienausgabe (Band II). Frankfurt am Main: Fischer.

Freud, S. (1921/1982b). Massenpsychologie und Ich-Analyse. In A. Mitscherlich, A. Richards \& J. Strachey (Eds.). Sigmund Freud: Studienausgabe (Band IX, pp. 61-134). Frankfurt am Main: Fischer.

Freud, S. (1950/1987). Entwurf einer Psychologie. In Gesammelte Werke (Nachtragsband) (pp. 373-486). Frankfurt am Main: Fischer.

Freud, S. (1891/1992). Zur Auffassung der Aphasien: eine kritische Studie. Frankfurt am Main: Fischer Taschenbuch Verlag.

Gabbi, O. F. (2005). Sonhos, pensamentos, palavras. In L. Fulgêncio \& R. T. Simanke (Orgs.). Freud na filosofia brasileira (pp. 169-202). São Paulo: Escuta 
Hegel, G. W. F. (1932/1975). Jenaer Systemwürfe I: Das System der spekulativen Philosophie. In K. Düsing \& H. Kimmerle (Eds.). Gesammelte Werke (Band VI). Hamburg: Meiner.

Hegel, G. W. F. (1907/1941). La phénoménologie de l'esprit (Jean Hyppolite, Trad.). Paris: Aubier.

Kojève, A. (1947/2002). Introdução à leitura de Hegel. Rio de Janeiro: Contraponto e EDUERJ.

Lacan, J. (1970). Radiophonie. Scilicet, 2\3, 55-99.

Lacan, J. (1975). Le Séminaire, Livre I: Les écrits téchnique de Freud, 1953-1954. Paris: Seuil.

Macherey, P. (1991). Lacan avec Kojève: philosophie et psychanalyse. In: Lacan avec les philosophes (pp. 315-322). Paris: Albin Michel.

Merleau-Ponty, M. (1960). Le philosophe et son ombre. In: Signes (pp. 201-228). Paris: Gallimard.

Safatle, V. (2005). A paixão do negativo: Lacan e a dialética. São Paulo: EDUNESP.

Simanke, R. T. (2002). Metapsicologia lacaniana: os anos de formação. São Paulo: Discurso Editorial e FAPESP.

Simanke, R. T. (2003). A letra e o sentido do "retorno a Freud" de Lacan: a teoria como metáfora. In: V. Safatle (org.). Um limite tenso: Lacan entre a filosofia e a psicanálise (pp. 277-303). São Paulo: EDUNESP.

Simanke, R. T. (2005). Nem filósofo, nem antifilósofo: notas sobre o papel das referências filosóficas na construção da psicanálise lacaniana. Natureza Humana, 7 (1), 9-58.

Simanke, R. T. (2010). Metapsicología de la representación: fundamentos del psicoanálisis freudiano y las ciencias de la mente contemporáneas. Devenires - Revista de Filosofía y de Filosofía de la Cultura, 22, 109-135.

Simanke, R. T. (2015). A neutralização do corpo na história da psicanálise. In C. A. F. Silva \& M. J. Müller (orgs.). Merleau-Ponty em Florianópolis (pp. 125-168). Porto Alegre: Editora Fi. 
Simanke, R. T. (2016a). A estátua, o autômato e o cadáver: a neutralização do corpo no pensamento de Jacques Lacan. Dois Pontos - Revista de Filosofia (no prelo).

Simanke, R. T. (2016b). Meaning and object in Freud's metapsychology (manuscrito em preparação). 